\title{
Safety and Efficacy of Single-Port Laparoscopic Ileostomy in Palliative Settings
}

\author{
Seng-Muk Kang*, Jung Rae Cho*, Heung-Kwon Oh, Eun-Ju Lee, Min Hyun Kim, Duck-Woo Kim, \\ Sung-Bum Kang \\ Department of Surgery, Seoul National University Bundang Hospital, Seoul National University College of Medicine, Seongnam, Korea
}

Purpose: Single-port laparoscopic techniques can be optimized with confined incisions. This approach has an intraoperative advantage of excellent visualization of the correct intestinal segment for exteriorization, along with direct visual control of the extraction to avoid twisting. However, only a few studies have verified the efficacy of the technique. Thus, this study assessed the results of single-port laparoscopic stoma creation for fecal diversion, specifically focusing on feasibility, safety, and efficacy.

Methods: Patients who underwent single-incision enterostomy performed by a single surgeon were included. Data on demographics, indications for and chosen procedure, and operation results were retrospectively collected and analyzed.

Results: Between April 2015 and January 2018, a total of 13 patients (8 males, 5 females) with a mean age of 57.7 years (range, 41-83 years) underwent single-port ileostomy creation. The most common reason for diversion was palliative ileostomy for colon obstruction or fistula from peritoneal malignancy $(n=12)$, followed by colonic fistula with necrotizing pancreatitis $(\mathrm{n}=1)$. There were no cases of conversion to open or multiport laparoscopic surgery. The mean operative time was 54 minutes (range, 37-118 minutes), and the median length of hospital stay was 8 days (range, 2-211 days). A postoperative complication, aspiration pneumonia, was documented in 1 patient and treated conservatively. The mean duration of bowel movement was 0.7 days (range, $0-4$ days). All stomas had good function, and there was no 30 -day mortality. Conclusion: Single-port laparoscopic ileostomy in patients with a palliative setting could be a safe and feasible option for fecal diversion.

Keywords: Single-port laparoscopic ileostomy; Postoperative complications; Safety; Palliative surgery

\section{INTRODUCTION}

The first laparoscopic cholecystectomy was performed by Mouret in 1987 (quoted from [1]); since then, minimally invasive surgeries have been the focus of research. The tendency of these procedures to minimize postoperative complications and maximize

Received: January 12,2019 • Accepted: April 25, 2019

Correspondence to: Heung-Kwon Oh. M.D.

Department of Surgery, Seoul National University Bundang Hospital, 82 Gumi-ro 173beon-gil, Bundang-gu, Seongnam 13620, Korea Tel: +82-31-787-7105, Fax: +82-31-787-4055, E-mail: crsohk@gmail.com ORCID: https://orcid.org/0000-0002-8066-2367

*Seng-Muk Kang and Jung Rae Cho contributed equally to this article.

(c) 2020 The Korean Society of Coloproctology

This is an open-access article distributed under the terms of the Creative Commons Attribution NonCommercial License (https://creativecommons.org/licenses/by-nc/4.0) which permits unrestricted noncommercial use, distribution, and reproduction in any medium, provided the original work is properly cited. cosmesis has led to widespread adoption of laparoscopic techniques in surgical procedures. Researchers have recently progressed from conventional laparoscopic modalities, with the aim of reducing the number of laparoscopic ports [2-4]. Use of a single-port laparoscopic technique has been suggested in stoma formation surgery as a method for decreasing patient burden during and after surgery.

Because the single-port laparoscopic technique uses a single access point, it is expected to have advantage over conventional laparoscopic techniques in terms of postoperative complications, wound cosmesis, and morbidity [5-7]. To date, multiple studies have shown that the single-port laparoscopic technique is safe and feasible and comparable to the conventional technique [8-10]. However, compared with the conventional laparoscopic procedure, there is currently no consensus on the superiority of the single-port procedure. Some studies have observed no significant difference between single-port and conventional laparoscopic 


\section{Annals of Safety and Efficacy of Single-Port Laparoscopic lleostomy in Palliative Settings \\ Coloproctology seng-Muk Kang, et al}

procedures [11, 12], while other studies have shown benefits of the single-port procedure over the conventional procedure [13, 14]. Some studies even expressed concern about the difficulty and time consumption of the surgical procedure, which can be taxing on the surgeon $[15,16]$.

Enterostomy, the formation of a stoma, is a surgical modality for inserting a feeding tube or allowing fecal diversion by opening the intestine and passing it through the patient's abdominal wall. It is performed in cases where the intestines are no longer functioning normally. The single-port laparoscopic procedure seems easily applicable to enterostomy, as the stoma requires a solitary incision, without additional wounds $[17,18]$. The approach also has the intraoperative advantage of excellent visualization of the correct intestinal segment for exteriorization, along with direct visual control of the extraction, to avoid twisting.

The number of studies published in this area is insufficient for verifying the efficacy of the laparoscopic technique, and more detailed and standardized verification is needed before the proce- dure can be adopted widely. Therefore, we conducted this study to assess the results of single-port laparoscopic stoma creation for fecal diversion, specifically focusing on the feasibility, safety, and efficacy.

\section{METHODS}

\section{Patient selection}

Single-port laparoscopic ileostomy was performed in 13 patients that needed fecal diversion at Seoul National University Bundang Hospital (Seongnam, Korea) between May 2015 and July 2018. The Institutional Review Board of the Seoul National University Bundang Hospital approved this study prior to commencement of data collection and analysis and waived the requirement for informed consent (B-1901-516-101).

\section{Surgical procedure}

The surgery was performed by a single surgeon. Under general
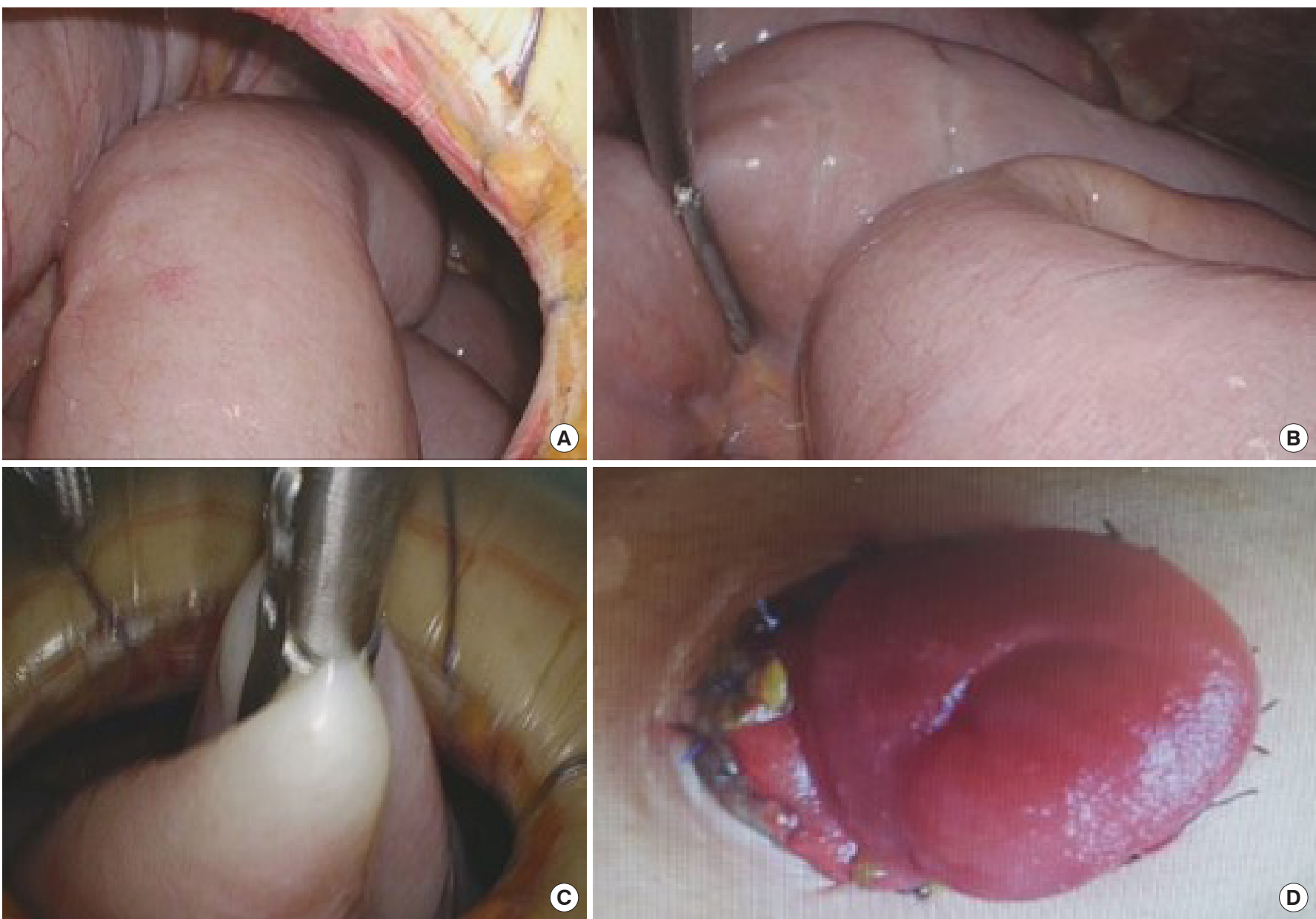

Fig. 1. Operative snapshot from the single-port ileostomy procedure. (A) Whole peritoneal cavity exploration. (B) Appropriate intestinal segment selection. (C) Exteriorization via a single-post incision site. (D) Maturation of ileostomy. 
anesthesia, the patient was placed in the supine position. A single, 2.5-cm-wide, circular incision was made at the ileostomy site, normally the left lower quadrant of the abdomen within the rectus abdominis muscle. After deepening into the peritoneum, a 4-appendage single port (Gloveport, Nelis, Bucheon, Korea) was inserted.

Laparoscopy was performed using a 10-mm flexible scope (Olympus, Tokyo, Japan) for better visualization of tight spaces. A full laparoscopic evaluation was performed to evaluate the presence of relevant pathology (Fig. 1A). The small bowel was traced, and the distal ileal segment for ileostomy formation was identified (Fig. 1B). After removal of the glove port, the ileal segment was

Table 1. Clinicopathologic patient characteristics

\begin{tabular}{|c|c|}
\hline Characteristic & Value \\
\hline Age (yr) & $57.7(41-83)$ \\
\hline \multicolumn{2}{|l|}{ Sex } \\
\hline Male & $8(61.5)$ \\
\hline Female & $5(38.5)$ \\
\hline Body mass index (kg/m²) & $17(10.702-21.894)$ \\
\hline \multicolumn{2}{|l|}{ Location of stoma } \\
\hline Right lower quadrant & $5(38.5)$ \\
\hline Left lower quadrant & $8(61.5)$ \\
\hline \multicolumn{2}{|l|}{ Indication for diversion operation } \\
\hline Obstruction & $10(76.9)$ \\
\hline Colonic obstruction & 7 (53.8) \\
\hline Small bowel obstruction & $3(23.0)$ \\
\hline Colonic fistula formation & $3(23.0)$ \\
\hline Tumor induced & $2(15.3)$ \\
\hline Pancreatitis induced & $1(7.7)$ \\
\hline \multicolumn{2}{|l|}{ Primary disease } \\
\hline Cancer & $12(92.3)$ \\
\hline Gastrointestinal cancer & $9(69.2)$ \\
\hline Advanced gastric cancer & $4(30.7)$ \\
\hline Colon cancer & $3(23.0)$ \\
\hline Cholangiocarcinoma & $1(7.7)$ \\
\hline Gall bladder cancer & $1(7.7)$ \\
\hline Gynecologic cancer & $2(15.3)$ \\
\hline Urologic cancer & $1(7.7)$ \\
\hline Necrotizing pancreatitis & $1(7.7)$ \\
\hline Previous operational history & 7 (53.8) \\
\hline Total gastrectomy & $3(23.0)$ \\
\hline Distal gastrectomy with gastrojejunostomy & $1(7.7)$ \\
\hline Right hemicolectomy & $1(7.7)$ \\
\hline Total abdominal hysterectomy & $2(15.3)$ \\
\hline
\end{tabular}

Values are presented as mean (range) or number (\%). retrieved and anchored to the fascia of the incision site (Fig. 1C). The ileostomy was matured in the normal fashion (Fig. 1D).

\section{Statistics and ethics}

Patient demographics were retrospectively retrieved from the data warehouse of Seoul National University Bundang Hospital. The demographics were sex, age, original disease, stage of tumor, body mass index, previous operational history, complete blood cell count, admission panel, and C-reactive protein level. Continuous variables are presented as the mean \pm standard deviation or the median and range. Categorical variables are presented as percentage of patients. All statistical analyses were performed using IBM SPSS Statistics ver. 21.0 (IBM Co., Armonk, NY, USA).

\section{RESULTS}

Between April 2015 and January 2018, a total of 13 patients underwent single-port ileostomy creation. Patient demographics and indications, procedures, and results of operation were analyzed. Patient demographics are listed in Table 1. The mean age of the patients was 57.7 years (range, $41-83$ years). Among them, 8 patients were male, and 5 were female. The mean body mass index of the patients was $17 \mathrm{~kg} / \mathrm{m}^{2}$ (range, $10.7-21.9 \mathrm{~kg} / \mathrm{m}^{2}$ ), and 7 patients $(53.8 \%)$ had previous operational history. The most common reason for diversion was palliative ileostomy for colon obstruction or fistula from peritoneal malignancy $(n=12)$, whereas only 1 patient had undergone diversion for colonic fistula with necrotizing pancreatitis. Among the malignant cancers, 9 (69.2\%) had gastrointestinal cancer, 2 (15.3\%) had gynecologic cancer, and $1(7.7 \%)$ had urologic cancer.

The postoperative outcomes are listed in Table 2. The mean operative time for stoma creation was 54 minutes (range, 37-118 minutes). The median length of hospital stay was 8 days (range, 2-211 days). Postoperative complication was documented in 1 patient $(7.7 \%)$ who experienced aspiration pneumonia after Levin tube insertion and was treated conservatively. The mean duration of bowel movements was 0.7 days (range, $0-4$ days) after surgery. During follow up, all stomas had good function, and none of the patients experienced postoperative 30-day mortality.

Table 2. Postoperative outcomes

\begin{tabular}{lc}
\hline Variable & Value \\
\hline Operative time (min), mean (range) & $54(37-118)$ \\
Time to flatulence (day), mean (range) & $0.6(0-2)$ \\
Duration to bowel movement (day), mean (range) & $0.7(0-4)$ \\
Length of postoperative hospital stay (day), median (range) & $8(2-211)$ \\
No. of postoperative complications (\%) & $1(7.7)$ \\
Aspiration pneumonia & 1 \\
\hline
\end{tabular}




\section{DISCUSSION}

In our series, 13 loop ileostomies were performed by a single surgeon, using the single-port laparoscopic procedure. Our study focused on verifying the efficacy and feasibility of the procedure, with the expectation that a single-incision approach could be superior to the conventional modality in terms of cosmesis, pain control, and operative outcome since it minimized the number of ports inserted into a patient's body, reducing patient operative burden. Because conventional laparoscopic procedures have become more popular in surgical fields because of their superiority in terms of safety, postoperative complication control, infection control, and cosmesis over laparotomy [19, 20], our data support a single-port laparoscopic modality as a safe, efficient, and feasible alternative to the conventional multiport laparoscopic procedure.

Based on the results, there was no postoperative 30-day mortality, and only 1 patient had a postoperative complication, aspiration pneumonia, because of Levin tube insertion and not because of the surgery itself. Therefore, the presence of postoperative complications cannot be used as a basis to assess the operative risk of the single-port laparoscopic approach. Our results were compared to those of conventional laparoscopic approaches, and the mean operation time and postoperative mortality were also comparable [21, 22]. When these results were combined with the results of other studies, it is evident that laparoscopic ileostomy using a single port is as safe as the conventional multiport procedure $[5,6,23]$.

The cost-effectiveness of procedures is important, especially when considering adaptation of a new technology. Cost analysis of the laparoscopic approach compared with that of laparotomy has been performed by several researchers. The initial operative costs of the laparoscopic maneuver are counterbalanced with reduced morbidity and length of hospital stay in the laparoscopic technique [24]. In this series of procedures, we used existing laparoscopic instrumentation and did not need to purchase new instruments, with the exception of the access port. Furthermore, the sum of the costs of ports used in the multiport maneuver exceeded the cost of the one port used here. Therefore, there should be no concerns over cost increases for purchasing extra instruments. Moreover, comparing the single-port maneuver with the conventional multiport maneuver, insertion of a smaller number of ports could provide a reduction of surgical costs since fewer instruments are needed. Reduction of the number of trocars needed for surgery led to reduction of the cost [23]. The smaller number of ports also led to a smaller number of wounds after surgery. Therefore, from a cosmetic perspective, the single-port laparoscopic procedure is superior to conventional multiport laparoscopic procedures. The smaller number of wounds also led to decreased pain $[6,25]$.

There were some limitations to our study, which include the retrospective nature, lack of a control group, and the small sample size of the patient group. Therefore, additional studies are needed to validate the results of this study. Our data coincide with the results of other studies, which will be important when assessing these results in future research. Although there are many advantages to single-port surgery, there are also conditions that can make it difficult to apply, which include a severe obstructed bowel, un-decompressed bowel edema, frozen abdomen owing to peritoneal seeding, and repeated open abdominal surgery.

In conclusion, based on the data from this study and other relevant studies, single-port laparoscopic ileostomy for fecal diversion could be adopted as a safe and feasible option in patients with a palliative setting.

\section{CONFLICT OF INTEREST}

No potential conflict of interest relevant to this article was reported.

\section{REFERENCES}

1. Cuschieri A, Dubois F, Mouiel J, Mouret P, Becker H, Buess G, et al. The European experience with laparoscopic cholecystectomy. Am J Surg 1991;161:385-7.

2. Danforth RM, Monn MF, Spera LJ, Fajardo AD, George VV. Safety and short-term outcomes of a single-port laparoscopic approach to colorectal surgery. JAMA Surg 2015;150:1195-7.

3. Lee WS, Choi ST, Lee JN, Kim KK, Park YH, Lee WK, et al. Single-port laparoscopic appendectomy versus conventional laparoscopic appendectomy: a prospective randomized controlled study. Ann Surg 2013;257:214-8.

4. Ma J, Cassera MA, Spaun GO, Hammill CW, Hansen PD, Aliabadi-Wahle S. Randomized controlled trial comparing single-port laparoscopic cholecystectomy and four-port laparoscopic cholecystectomy. Ann Surg 2011;254:22-7.

5. Omar MA, Redwan AA, Mahmoud AG. Single-incision versus 3-port laparoscopic cholecystectomy in symptomatic gallstones: A prospective randomized study. Surgery 2017;162:96-103.

6. Aly OE, Black DH, Rehman H, Ahmed I. Single incision laparoscopic appendicectomy versus conventional three-port laparoscopic appendicectomy: A systematic review and meta-analysis. Int J Surg 2016;35:120-8.

7. Haueter R, Schütz T, Raptis DA, Clavien PA, Zuber M. Metaanalysis of single-port versus conventional laparoscopic cholecystectomy comparing body image and cosmesis. Br J Surg 2017;104: 1141-59.

8. Gaujoux S, Maggiori L, Bretagnol F, Ferron M, Panis Y. Safety, feasibility, and short-term outcomes of single port access colorectal surgery: a single institutional case-matched study. J Gastrointest Surg 2012;16:629-34.

9. Wolthuis AM, Penninckx F, Fieuws S, D'Hoore A. Outcomes for case-matched single-port colectomy are comparable with conventional laparoscopic colectomy. Colorectal Dis 2012;14:634-41.

10. Tanaka E, Fukunaga Y, Nakashima M, Nagasue Y, Akiyoshi T, 
Konishi T, et al. Laparoscopic incisionless stoma creation for patients with colorectal malignant stricture. Surg Laparosc Endosc Percutan Tech 2015;25:37-9.

11. Hasegawa J, Hirota M, Kim HM, Mikata S, Shimizu J, Soma Y, et al. Single-incision laparoscopic stoma creation: experience with 31 consecutive cases. Asian J Endosc Surg 2013;6:181-5.

12. Shah A, Moftah M, Hadi Nahar Al-Furaji H, Cahill RA. Standardized technique for single port laparoscopic ileostomy and colostomy. Colorectal Dis 2014;16:O248-O252.

13. Papaconstantinou HT, Sharp N, Thomas JS. Single-incision laparoscopic right colectomy: a case-matched comparison with standard laparoscopic and hand-assisted laparoscopic techniques. J Am Coll Surg 2011;213:72-80.

14. Deng L, Xiong J, Xia Q. Single-incision versus conventional threeincision laparoscopic appendectomy: a meta-analysis of randomized controlled trials. J Evid Based Med 2017;10:196-206.

15. Costedio MM, Remzi FH. Single-port laparoscopic colectomy. Tech Coloproctol 2013;17 Suppl 1:S29-S34.

16. Ross H, Steele S, Whiteford M, Lee S, Albert M, Mutch M, et al. Early multi-institution experience with single-incision laparoscopic colectomy. Dis Colon Rectum 2011;54:187-92.

17. Yagi R, Kameyama H, Nakano M, Sato Y, Kido T, Nakano M, et al. [Single-port laparoscopic stoma creation for fecal diversion experience of ten consecutive patients]. Gan To Kagaku Ryoho 2014;41:1643-4.

18. Miyoshi N, Fujino S, Ohue M, Yasui M, Noura S, Wada Y, et al. Standardized technique for single-incision laparoscopic-assisted stoma creation. World J Gastrointest Endosc 2016;8:541-5.

19. Tan S, Wu G, Zhuang Q, Xi Q, Meng Q, Jiang Y, et al. Laparoscopic versus open repair for perforated peptic ulcer: a meta analysis of randomized controlled trials. Int J Surg 2016;33 Pt A:124-32.

20. Martínez-Pérez A, de’Angelis N, Brunetti F, Le Baleur Y, PayáLlorente C, Memeo R, et al. Laparoscopic vs. open surgery for the treatment of iatrogenic colonoscopic perforations: a systematic review and meta-analysis. World J Emerg Surg 2017;12:8.

21. Liu J, Bruch HP, Farke S, Nolde J, Schwandner O. Stoma formation for fecal diversion: a plea for the laparoscopic approach. Tech Coloproctol 2005;9:9-14.

22. Marshall RE, McPartlin JF. Laparoscopic stoma formation for faecal diversion. Br J Surg 1998;85:1161-2.

23. Lee YS, Kim JH, Moon EJ, Kim JJ, Lee KH, Oh SJ, et al. Comparative study on surgical outcomes and operative costs of transumbilical single-port laparoscopic appendectomy versus conventional laparoscopic appendectomy in adult patients. Surg Laparosc Endosc Percutan Tech 2009;19:493-6.

24. Franks PJ, Bosanquet N, Thorpe H, Brown JM, Copeland J, Smith AM, et al. Short-term costs of conventional vs laparoscopic assisted surgery in patients with colorectal cancer (MRC CLASICC trial). Br J Cancer 2006;95:6-12.

25. Lurje G, Raptis DA, Steinemann DC, Amygdalos I, Kambakamba $\mathrm{P}$, Petrowsky $\mathrm{H}$, et al. Cosmesis and body image in patients undergoing single-port versus conventional laparoscopic cholecystectomy: a multicenter double-blinded randomized controlled trial (SPOCC-trial). Ann Surg 2015;262:728-34. 